\title{
Experiential Training for Pharmacy Students: Time for a New Approach
}

\author{
Kevin Hall, Emily Musing, Douglas A Miller, and James E Tisdale
}

\section{INTRODUCTION}

$\mathrm{T}$ he pharmacy profession in Canada finds itself in the midst of transformational change. The regulation and expanded scope of practice of pharmacy technicians that is under way across the country, combined with the advent of new drug distribution technologies in both the hospital and community practice settings, have created the opportunity for pharmacists to largely relinquish their traditional role in the drug distribution system. This change will permit pharmacists to take on new and expanded patient-centred roles and responsibilities. However, patient-centred care requires a different set of skills and training (e.g., clinical practice skills, critical thinking skills, decision-making skills under conditions of uncertainty, collaborative interpersonal practice skills) than those that were needed to be a good pharmacist in the past (e.g., attention to detail, accuracy, risk aversion). Pharmacy educational programs will have to produce confident graduates who are able and willing to assume responsibility and accountability for drug therapy management.

Experiential training is viewed as an essential requirement for the development of these skills. As the profession moves forward with implementation of the Vision for Pharmacy contained within the Blueprint for Pharmacy, ${ }^{1}$ there has been considerable debate about the type of experiential training programs that will best prepare pharmacy students for their future role. There has also been debate about whether the desired quality and quantity of such training can be delivered using the experiential training models currently in place across the country. This paper provides background and context regarding the changes that are driving the current debate, as well as the challenges that hospitals face in delivering quality experiential programs with existing training models. Alternatives that have been proposed or already implemented are presented and discussed. Finally, a set of principles is proposed for future experiential training models in the hospital setting.

\section{BACKGROUND}

Existing experiential training models for pharmacy students have been criticized for a number of perceived deficiencies. The relatively short duration of experiential rotations, combined with the common practice of moving pharmacy students to different sites so that they are exposed to a variety of practice environments, leads to a situation in which many structured practical experiential program (SPEP) rotations are little more than "observerships". ${ }^{2}$ Students are given minimal opportunity to assume any responsibility or accountability for the development of drug therapy treatment plans and their associated outcomes. As a result, many preceptors and hospital pharmacy administrators view experiential students as a burden, rather than as contributing members of the health care team. Students are allowed virtually no independence and, in many institutions, are accompanied by a preceptor at all times when present on a patient care unit or when interacting with other health care professionals.

With the recent increase in the number of students being admitted to pharmacy programs in Canada and the advent of entry-level Doctor of Pharmacy (PharmD) programs in Canada, the demand for student training sites is increasing at the same time as hospitals and community practice sites are becoming increasingly reluctant to invest further resources into the provision of experiential training that provides little perceived value to the hosting organization. To understand how the pharmacy profession arrived at this point, and what might be done to turn the challenges into opportunities, we first look back at developments in the profession over the past few decades. We then describe a novel approach to experiential training that was implemented at a US academic institution about 10 years ago. Finally, we propose a set of principles for consideration by faculties of pharmacy, hospital pharmacy administrators, and hospital pharmacist preceptors as they attempt to address the challenges associated with existing 
experiential training models and weigh the benefits and costs of pursuing alternative models.

\section{ENVISIONED ROLE OF PHARMACISTS VERSUS REALITY}

In the mid-1970s, Don Francke, editor of the journal Drug Intelligence and Clinical Pharmacy (now the Annals of Pharmacotherapy), wrote "I would establish as the principal qualifications of a clinical practitioner that he bear personal responsibility for the safe and effective use of drugs in a number of patients on a continuing basis." ${ }^{3}$ Over the 40 years since Francke proposed that description of the pharmacist's role, progress toward this goal has been slow and incomplete. For example, in responding to the 2009/2010 Hospital Pharmacy in Canada survey, pharmacy managers at 143 acute care organizations reported that only $14 \%$ of pharmacists in the hospital pharmacy setting were functioning primarily in clinical roles, with most of the remaining pharmacists functioning primarily in either a drug distribution role (17\%) or a mixed clinical and drug distribution role (63\%). ${ }^{4}$

Speculation about reasons for the slow pace of change has fuelled many debates within the profession. Some have argued that few pharmacists have been given the tools, such as prescribing authority, that would be required if they are to manage drug therapy. However, even in those jurisdictions where governments have introduced prescribing rights for pharmacists, or other changes that would allow pharmacists to participate more fully in the management of drug therapy, many pharmacists have been reluctant to take on the expanded scope of practice that has been made available to them. For example, according to the Alberta College of Pharmacists (Dale Cooney, Deputy Registrar, personal communication by e-mail, March 28, 2012), fewer than $4 \%$ of Alberta pharmacists have completed the requirements to obtain the "additional prescribing authority" that was granted to pharmacists in that province in 2007. ${ }^{5}$ Recent studies have also suggested that pharmacists in both the community and hospital pharmacy settings continue to view drug distribution as their primary role. ${ }^{6,7}$ However, many initiatives now under way across Canada, such as the regulation or expanded scope of practice of pharmacy technicians and the increased use of automation in the drug distribution system, will inevitably result in major changes in the roles and responsibilities of pharmacists.

\section{SPECIAL INITIATIVES: MOVING FORWARD AND BLUEPRINT FOR PHARMACY}

Many of the changes with which pharmacy in Canada is now grappling result from work undertaken as part of the Moving Forward ${ }^{8,9}$ and the Blueprint for Pharmacy ${ }^{1,10}$ initiatives, which began in the mid to late 2000s. Research performed for the Moving Forward initiative provided both the profession and government decision-makers with clear evidence that pharmacists represent an underutilized health human resource. ${ }^{8}$ A compelling case was made that better use of pharmacists could help to alleviate numerous deficiencies in the health care system, including the burden of preventable drug-induced disease; failure to maximize the benefits achievable through appropriate medication management; and patients' difficulties in accessing primary care physicians for medication-related needs that could be efficiently, effectively, and safely dealt with by pharmacists. At the same time, sound arguments have been made that appropriately trained pharmacy technicians, working under the general supervision of a pharmacist, can assume responsibility for most aspects of the drug distribution system, thus freeing up pharmacists to perform high-value medication therapy management activities. Medication therapy management has been defined as "a group of services that optimize therapeutic outcomes for individual patients and include such activities as formulating a medication treatment plan; selecting, initiating, modifying or administering medication therapy; and monitoring and evaluating a patient's response to therapy." ${ }^{11}$

During the Moving Forward project, several groups (e.g., deans of pharmacy faculties, employers, pharmacists) were surveyed about their thoughts on the ability and willingness of pharmacists to assume the new role of "medication therapy manager". A number of participants in the Moving Forward surveys and focus groups felt that there was a shortage of confident graduates emerging from faculties of pharmacy who were both able and willing to accept responsibility and accountability for drug therapy management. ${ }^{8}$ Some participants suggested that there was an urgent need to reconstruct the professional culture of pharmacy and that doing so would require new experiential training models to help teach critical thinking skills to pharmacy students and to assist them in developing decision-making skills in the clinical practice environment. Experiential training would need to be designed to gradually increase, over the duration of the pharmacy program, students' responsibility and accountability for patient outcomes associated with drug therapy. The medical training model, where such a progression of responsibility and accountability occurs over the course of the academic program, was suggested as a model that pharmacy should consider. ${ }^{8}$

In its final report, the Moving Forward Management Committee made a recommendation to "Increase the number and variety of quality experiential training opportunities necessary to prepare pharmacists, pharmacy technicians and students to practise in expanded and innovative roles." 9 The background to this recommendation made reference to several important issues that the profession is facing. Most faculties of pharmacy have increased their enrolment numbers in response to the shortage of pharmacists that developed in the late 1990s and the 2000s. More specifically, according to the Association of Faculties of Pharmacy of Canada, total 4-year enrolment in the faculties of pharmacy increased by $50 \%$ during the 2000 s (Table 1). In addition to these enrolment changes, introduction 
Table 1. Enrolment History for Canadian Faculties of Pharmacy*

Academic Year; Total No. of Undergraduates in 4-Year Program

\begin{tabular}{|c|c|c|c|c|c|c|c|}
\hline \multirow[b]{2}{*}{ Faculty } & & & & & & & \\
\hline & $2000 / 2001$ & $2004 / 2005$ & $2005 / 2006$ & $2006 / 2007$ & $2007 / 2008$ & $2008 / 2009$ & $2009 / 2010$ \\
\hline University of British Columbia & 551 & 563 & 568 & 576 & 599 & 599 & 613 \\
\hline University of Alberta & 420 & 463 & 490 & 505 & 512 & 513 & 513 \\
\hline University of Saskatchewan & 307 & 329 & 338 & 349 & 352 & 347 & 354 \\
\hline University of Manitoba & 192 & 196 & 200 & 191 & 195 & 197 & 193 \\
\hline University of Toronto & 473 & 723 & 801 & 863 & 912 & 949 & 951 \\
\hline University of Waterloot & NA & NA & NA & NA & 93 & 205 & 318 \\
\hline University of Montreal & 478 & 636 & 659 & 684 & 684 & 721 & 732 \\
\hline Université Laval & 378 & 567 & 560 & 559 & 575 & 575 & 583 \\
\hline Dalhousie University & 257 & 353 & 352 & 359 & 359 & 359 & 351 \\
\hline \multicolumn{8}{|l|}{ Memorial University of } \\
\hline Newfoundland & 114 & 111 & 115 & 118 & 118 & 160 & 162 \\
\hline Total & 3170 & 3941 & 4083 & 4204 & 4399 & 4625 & 4770 \\
\hline
\end{tabular}

NA = not applicable.

*Data provided by Association of Faculties of Pharmacy of Canada (Harold Lopatka, Executive Director, personal communication by e-mail, March 17, 2010).

†The faculty of pharmacy at the University of Waterloo became operational in 2007/2008, when it had only first-year students. By 2009/2010, the faculty had first-, second-, and third-year students, and the first class graduated in spring 2011.

of the PharmD as the first professional degree offered by faculties of pharmacy in Canada will have significant implications for experiential education requirements. A major increase in the length of time spent in experiential training is one of the defining features of the proposed entry-to-practice PharmD programs. The most recent accreditation standards for Canadian faculties of pharmacy will continue to require that students in Bachelor of Science in Pharmacy programs complete a minimum of $640 \mathrm{~h}$ (16 weeks) of practice experience over the course of their programs, whereas students in entry-to-practice PharmD programs will be required to complete $1600 \mathrm{~h}$ ( 40 weeks) of practice experiences (Dr Wayne Hindmarsh, Executive Director, CCAPP; personal communication by e-mail, July 3, 2012). The ability to secure a sufficient number of placements of appropriate duration to meet these increased experiential requirements will be an important consideration as faculties move forward with their stated plans to implement entry-to-practice PharmD programs by $2020 .^{12}$ For hospitals and other organizations that serve as sites for the delivery of experiential training, increased student enrolment, combined with the substantial increase in practice experience requirements that will be associated with introduction of the PharmD degree, could represent a "perfect storm".

The final report of the Moving Forward project" recognized that accommodating increased numbers of students for experiential training would only be possible if the hosting organizations (e.g., hospitals, community pharmacies) perceived that they were receiving value in return for their contribution to the training of pharmacy students. Faculties of pharmacy, in collaboration with other pharmacy stakeholders, were encouraged to clearly define what value the hosting organizations should expect to receive in return for hosting experiential training rotations. It was also recommended that, subsequent to the establishment of a consensus concerning what that value should entail, the faculties and the profession clearly articulate the value to regional health authorities, hospital pharmacies, community pharmacies, governments, and other health care providers.' For example, a number of papers have highlighted various student-delivered pharmacy services and activities that have been shown to have a positive impact on patient outcomes (e.g., attendance at patient care rounds, patient interviews and assessments, medication reconciliation, discharge counselling, follow-up after discharge). ${ }^{13-19}$ Students could progressively be given greater responsibility and accountability for subsets of these activities as they progress through their programs.

During the Moving Forward consultations, the deans of pharmacy also expressed concerns regarding the quantity and quality of both community and hospital pharmacy practice sites where the experiential training could be provided. Furthermore, given the important role that multidisciplinary teams of health professionals are expected to play in delivering health care services in the future, it was suggested that at least a portion of a student's experiential training should occur within the framework of multidisciplinary teams.

The Blueprint for Pharmacy initiative incorporated these themes into its Vision for Pharmacy, ${ }^{1}$ with objectives that included "Increase the accessibility, quality, quantity and variety of experiential learning opportunities" and "Promote and increase interprofessional and intraprofessional approaches to education and training". The Blueprint's Implementation $\operatorname{Plan}^{10}$ describes a number of deliverables related to experiential learning, some of which are listed here:

- secure funding to design, evaluate, and disseminate best practices of experiential learning

- create an inventory of best practices and examples of exemplary models in experiential learning

- create, evaluate, and disseminate new learning models

- support mechanisms for practitioners to offer experiential learning opportunities 
The Blueprint for Pharmacy Steering Committee recently announced funding for initial work toward achieving these deliverables. ${ }^{20}$

\section{EXPERIENTIAL TRAINING ISSUES IN THE HOSPITAL PHARMACY SETTING}

In Canada, traditional experiential training programs that are part of undergraduate pharmacy programs are commonly referred to as SPEPs. SPEPs for the Bachelor of Pharmacy degree at Canadian universities vary somewhat but must meet certain accreditation requirements, including at least $160 \mathrm{~h}$ of "early practice experiences" in the first year or two of the program and $480 \mathrm{~h}$ of "final practice experience" in the last year. ${ }^{21}$ As indicated previously, these experiential training requirements will increase substantially as entry-to-practice PharmD programs are adopted by Canadian faculties of pharmacy.

The design of traditional experiential rotations may differ somewhat from faculty to faculty, but they are often characterized by the following features:

- Rotations are of relatively short duration.

- Rotations occur at a number of different sites, with students required to undergo a period of orientation at the start of each rotation, rather than being able to quickly step into a pharmacy practice role.

- Because of the relatively short duration of rotations and the time required for orientation, early practice experiences, and sometimes later practice experiences, often end up being primarily "observerships", with little opportunity for the student to participate in the delivery of care in any meaningful way.

- Students are closely supervised, and the student-topharmacist ratio is very low, often 1:1.

- Students in late practice experiences are often required to complete a set number of certain activities (e.g., discharge counselling sessions), but it is uncommon for students, under limited supervision of a licensed pharmacist, to be given personal responsibility or accountability for providing care to patients.

A number of questions related to experiential training were included in the 2009/2010 Hospital Pharmacy in Canada survey, and responses from 157 hospitals and health authorities were included in the corresponding report. ${ }^{22}$ Most respondents (all 42 teaching hospitals and 100 [87\%] of 115 nonteaching hospitals) reported providing SPEP training for undergraduate pharmacy students. These numbers suggest limited potential to increase the quantity of experiential training by increasing the number of hospital sites that provide such training. Instead, hospitals already providing experiential training would have to be convinced to increase the number and/or duration of experiential training opportunities. However, responses to another SPEP-related question in the 2009/2010 survey suggested that the ability of existing SPEP training sites to increase the quantity of experiential training that they provide, using existing models, would be limited. The pharmacy directors who completed the survey were asked to prioritize the usefulness of 12 strategies ("enablers") that have been suggested as ways to increase experiential capacity in the hospital pharmacy setting. The 3 highest-ranked enablers were all related to addressing the heavy workload associated with experiential training in the traditional SPEP models (Table 2). Given these workload concerns and the budgetary constraints that hospitals face, it is doubtful that most hospitals would be able and willing to accommodate a substantial increase in experiential training.

A 74-item staff satisfaction survey conducted at the Winnipeg Regional Health Authority in 2007 and repeated in 2008 showed that 3 of the 4 items associated with the greatest degree of dissatisfaction among pharmacists were related to experiential training of pharmacy students (Winnipeg Regional Health Authority, unpublished data provided by Colette Raymond, Staff Development and Practice Evaluation Pharmacist, personal communication, December 2010). Specifically, pharmacists indicated that they did not have sufficient time to adequately mentor students, that the number of preceptorship days was unreasonable, and that the number of students was unreasonable. For the most part, current models require that preceptors take on the workload of providing experiential training without being relieved of any of their usual workload. This is clearly a challenge for many hospitals and their staff and presents a significant obstacle to the expansion of the traditional model used for experiential training. Even highly motivated pharmacists, who are committed to the experiential training of pharmacy students, find that the traditional models are not sustainable in the face of increasing demands for such training. Without a substantial infusion of additional pharmacist resources, most hospitals would have difficulty taking on additional students using the SPEP models currently in place.

Several other strategies to increase experiential training capacity were examined in the 2009/2010 Hospital Pharmacy in Canada survey. For example, the use of preceptors from other disciplines (nursing, medicine, etc.) was reported by $25 \%$ of respondents. Although the interdisciplinary nature of this approach has merit (and such an approach should be part of every pharmacy student's training), the responsibility for serving as primary preceptors for pharmacy students should rest with the members of the pharmacy profession. Pharmacist preceptors are most familiar with the outcomes required to meet accreditation standards, understand the role that pharmacists should play on collaborative health care teams, and are best positioned to ensure that the experiential educational objectives are met. In addition, the capacity and willingness of other 


\section{Table 2. Enablers for Expanding Structured Practice Experiential Programs*}

\section{Proposed Enabler}

Fewer competing demands in the workplace (i.e., reduced workloads)

Funding to provide backfill for preceptors who are providing experiential education

No pharmacist or technician vacancies in areas where students are being precepted

More flexibility in timing or scheduling of rotations

Dedicated university/technical college faculty who would assist with precepting students

Adequate space and equipment (e.g., computer access) to facilitate experiential education

Simplified evaluation forms and processes

Better prepared students

New or expanded preceptor training programs

Rotation coordinators/supervisors from the faculties/colleges who would be based at, or regularly visit, your facility

Access to electronic resources (e.g., library, journals)

Academic appointments for preceptors
Mean Usefulness

Rankingt

3.7

4.2

4.3

5.6

6.3

6.4

6.7

7.4

7.8

8.2

8.5

8.8

*Reproduced, with permission, from the Hospital Pharmacy in Canada 2009/2010 Report.22

tRanked from most useful to least useful, based on respondents who provided complete ranking $(n=134)$.

disciplines to assume a major role in the experiential training of pharmacy students is unlikely to be sufficient to support the needs of pharmacy educational programs.

The majority of respondents (55\%) reported that they assigned only one student to each preceptor. ${ }^{22}$ As such, SPEP training capacity could be expanded by adopting a model with more than one student assigned to each preceptor, similar to other disciplines, like medicine and nursing. A further $28 \%$ of respondents reported using other models, in which senior pharmacy students participate in the training of more junior pharmacy students. Such "peer-assisted" or "near-peer" training models have been used in medical training for many years. A peer-assisted training model in a hospital pharmacy setting was recently described, ${ }^{23}$ and the authors of a recent study on hospital pharmacy residency programs made a case for the pharmacy profession adopting the medical model. ${ }^{24}$ They argued that a system that integrates pharmacy students and hospital pharmacy residents into a peer or near-peer teaching model can provide significant benefits to the hosting hospital by increasing provision of services and patient coverage, while improving the experiential training of pharmacy students and residents. As a result, such peer or near-peer models would likely be welcomed by many hospitals, since they offer the potential to significantly increase the capacity for SPEP training of undergraduate pharmacy students. However, implementation of these types of training models would require a major change in the way that SPEP training is designed and scheduled throughout the entire undergraduate pharmacy program.

\section{AN INNOVATIVE EXPERIENTIAL TRAINING MODEL}

One innovative experiential training model has been developed to address many of the problems associated with existing models. In 2001 and 2002, two of the authors (D.A.M. and J.E.T.) helped to develop and subsequently participated in this new experiential training model, which was introduced at the Henry Ford Hospital in Detroit, Michigan, for PharmD students from the College of Pharmacy and Health Sciences at Wayne State University (WSU), also in Detroit. The pilot program used a Longitudinal Advanced Pharmacy Practice (LAPP) model, in which students completed 5 to 7 (of a total of 8) required 6-week rotations at a single hospital site. Traditionally, students had completed rotations at a variety of participating hospitals, often visiting a new site every 6 weeks. There were multiple reasons for implementing a new model. First, it was becoming increasingly difficult for the experiential coordinator at the college to find hospitals and preceptors willing to accept students on rotation. Much of the reluctance seemed to stem from a developing consensus that students were burdensome, adding significantly to departmental workload and negatively affecting clinical pharmacists' ability to provide quality patient care. With the traditional model, each student was typically assigned to accompany (i.e., "shadow") a single clinical pharmacist, whose job was to orient the student to the unit and to the pharmacist's roles and responsibilities. It could take several weeks to teach a student who was new to the hospital how to use computer systems and to orient him or her to hospital policy, procedures, and protocols. By the end of their 6-week rotations, most students were beginning to contribute to patient care, but the start-up process was labourintensive and had to be repeated each time a new student came to the hospital. Any contribution a student might make to providing patient care was far outweighed by these start-up costs.

Increasing reluctance to accept students was particularly worrisome to the university, given that it had converted to the entry-level PharmD program in 2000, a change that dramatically increased the need for quality experiential training rotations. PharmD students were required to participate in 48 
weeks of advanced clinical rotations during their final year in the program, whereas students in the 5-year Bachelor of Science program (which was phased out as a result of accreditation changes in the United States) had completed only 6 weeks of this type of training.

WSU was also interested in changing the nature of experiential rotations. As noted above, rotations had historically involved "shadowing" clinical practitioners. WSU students typically accompanied their pharmacist preceptor on patient care rounds, and any interactions between the student and patients or other health providers usually occurred under the preceptor's direct supervision. Students were observers of patient care much more than they were participants. As a result, they felt no "ownership" for the quality of care provided. A recent study by the American College of Clinical Pharmacy identified that this model of training continues to be used in some experiential programs, despite its limited educational value. $^{2}$ In 2001/2002, WSU decided to change that dynamic. The university wanted students to be active participants in, and feel responsible for, the care of assigned patients. It was understood, of course, that students would still require the supervision of a licensed pharmacist preceptor. However, most believed that students could accept increasing levels of responsibility as their skills developed and that it was possible to tailor the level of supervision to students' individual needs.

Hospitals in the area had their own dilemma: how to do more with less. The benefits of pharmacist-provided clinical services were reasonably well understood and appreciated, but the pressure to reduce health care costs, coupled with pharmacists' increasing salary demands, were making it progressively more difficult to provide those services. Service expansion, even where significant demand existed, had become extremely difficult to justify. Henry Ford Hospital needed a way to improve the efficiency of each of its clinical pharmacy practitioners and saw PharmD students as possible "pharmacist extenders" if the pharmacy practice model were changed. They thought it might be possible to emulate the pyramidal medical model, whereby care is provided by a team headed by an "attending" practitioner, who has overall responsibility for the quality of care and who supervises others (fellows, residents, students), who are largely responsible for the delivery of that care. However, to ensure proper patient care, any model would have to be functional all the time- - the model could not change from month to month according to whether or not students were available.

The LAPP program grew out of a need to solve both hospital and university issues. Redesign of the practice model at the hospital to incorporate students as "pharmacist extenders" allows existing hospital staff to provide care for more patients, creates better-quality rotations for students as they transition from observers to active participants in patient care, and helps resolve the university's problem of finding enough rotation sites for students by "making pharmacy students indispensable to the training site." ${ }^{25}$

In contrast to the traditional model of students moving to a different institution for a different rotation every 6 weeks, students in the LAPP program complete nearly all of their rotations at a single institution. Rotations outside of Henry Ford Hospital are allowed for specialty elective and community practice rotations that are not available within the hospital. Students who are interested in participating in the LAPP program formally apply and undergo an interview. During the first rotation of their final (clerkship) year of the PharmD program, students are oriented to the hospital's drug distribution system, drug information service, institutional policies and procedures, and clinical practice models. Following this orientation period, students are assigned to patient care teams for 6-week experiences in internal medicine, cardiology, neurology, nephrology, critical care, and other practice areas. The student serves as the clinical pharmacist on his or her assigned team and typically participates on rounds without the direct supervision of a pharmacist preceptor. This allows each student to develop relationships with the other health care professionals on the team and to assume increasing responsibility for the drug therapy outcomes of patients under his or her care. The preceptor provides daily supervision and support tailored to the student's needs and the requirement to ensure quality of care. The preceptor meets regularly with the student to discuss specific cases, to review patients' drug therapy, and to ensure that the goals and objectives of the rotation are being met. The typical patient load for a student is $10-15$ patients. This model is consistent with recommendation $\mathrm{B} 24 \mathrm{C}$ of the recent American Society of Health-System Pharmacists' Pharmacy Practice Model Initiative summit: "Develop a plan to allocate student time to drug-therapy management services." ${ }^{26}$

Henry Ford Hospital pilot-tested this program in 2001/2002, when 7 students were accepted into the program. Some rotations were created on patient care units that had not previously had clinical pharmacist coverage; as such, Henry Ford Hospital was able to expand its clinical pharmacy services through use of student pharmacists. Formal and informal surveys completed at the end of the pilot year indicated that the program was considered successful by the students, the hospital, and the university. The students felt that they benefited from a stronger learning experience than would have been possible with traditional "shadowing" experiences. In addition, they developed the independence and clinical skills to help ensure optimal drug therapy outcomes for their patients. The hospital was able to expand clinical pharmacy services without additional cost by integrating students into its practice model. ${ }^{2}$ Rather than seeing students as a burden, the hospital was able to utilize them to provide direct patient care. The university 
benefited from greater availability of high-quality rotation sites.

Other hospitals in the metropolitan Detroit area have now adopted the LAPP concept. Hospitals and interested students participate in a matching program similar to the American Society of Health-System Pharmacists' residency matching program to determine which students will complete their LAPP program at which practice site. Although outcome data have not been published, interviews with students, faculty, pharmacist preceptors, and other participants indicate that the program is very well received. The LAPP program at Henry Ford Hospital continues to operate effectively today and serves as a model for other colleges and schools of pharmacy and their practice sites. ${ }^{27}$

\section{GUIDING PRINCIPLES FOR A NEW APPROACH TO EXPERIENTIAL TRAINING}

Faced with many of the challenges described earlier in this paper, directors of pharmacy from 8 primary teaching sites linked to the University of Toronto (including E.M.) worked together over the summer of 2011 to identify some key success factors for future experiential training models. We have drawn from that work, our personal experiences, and recent publications ${ }^{2,24-28}$ to develop a set of principles that we believe should be considered in the design of future hospital-based pharmacy experiential training models:

1. Experiential training of pharmacy students should begin early in the educational program and should run in parallel with other components of the curriculum throughout the duration of the student's academic year.

2. Early practice experiences (i.e., in the first few years of the pharmacy program) should encompass both community and hospital practice settings, whereas the sustained practice experiences in later years should utilize a LAPP model, with the expectation that the student will accomplish a large portion of his or her hospital training at a single hospital or community site.

3. A matching program similar to that used by the Canadian Hospital Pharmacy Residency Board should be used for LAPP placements of pharmacy students in either community or hospital pharmacy practice settings. Students would attend interviews with various institutions, and both students and institutions would rank each other in the matching process. Over time, as it became clear that hosting experiential training rotations provides substantial benefit to the hospital, there would be a significant incentive for the hospital to design the best possible program (experience) for the students. An incentive would be created for motivated students to perform as well as possible, both academically and in extracurricular activities, so that they would be strong candidates in the view of institutions with a reputation for offering quality training experiences.
4. As for medical residents, pharmacy students participating in later practice experiences should be under the supervision of, but not constantly accompanied by, a pharmacist preceptor acting in an "attending" pharmacist" role. Over the course of their LAPP experience, students should progressively assume greater responsibility and accountability for the provision of patient care services.

5. Experiential training should incorporate peer or near-peer learning methods, in which students assist in teaching, training, and supervising other students.

6. Both early pharmacy practice experiences and later sustained pharmacy practice experiences should incorporate a required interdisciplinary training component. In the hospital setting, this could be achieved by having pharmacy students participate regularly in interdisciplinary patient care rounds or an interdisciplinary clinic. Although some universities have introduced interdisciplinary courses, in an effort to expose students to the roles played by other professionals, such classroom-based initiatives cannot replicate the experience of working together in a real-life patient care setting. It is unrealistic to expect that students who receive their experiential training largely in isolation from other health care disciplines will somehow transition smoothly into an interdisciplinary practice model after they graduate.

7. An evidence-informed process should be used to establish a set of patient care activities for which students can be expected to assume responsibility at different stages of their training. This would allow students to contribute to patient care at a level appropriate to their training, while providing them with valuable experience to support their transition from students to autonomous clinicians.

8. The Canadian Society of Hospital Pharmacists (CSHP) and the Association of Faculties of Pharmacy of Canada should take the lead in engaging hospital pharmacy practitioners, hospital pharmacy managers, and faculties of pharmacy in a process that would explore the issues facing experiential training of pharmacy students in the hospital pharmacy setting and develop the best possible models for the future. This would be consistent with the CSHP "Statement on Collaborative Development, Delivery and Evaluation of Pharmacy Curricula". ${ }^{29}$ With respect to this collaborative initiative, the CSHP would need to take care to respect the role, responsibility, and decision-making authority of faculties of pharmacy with respect to curriculum content. Similarly, faculties of pharmacy would need to respect the primary mandate of hospital pharmacy departments-patient care-and be open to exploring new models of experiential training that would both be manageable and provide patient care value to the hosting hospital. A similar initiative is undoubtedly warranted for experiential training models in the community pharmacy practice setting, which would need to involve the hosting 
organizations for community pharmacy rotations (e.g. community pharmacies, primary care practices).

We believe that implementation of these recommendations would provide a "win-win-win-win" scenario for pharmacy students, pharmacy preceptors, faculties of pharmacy, and health care institutions:

- $\quad$ Pharmacy students would no longer be simply observers or "shadowers". They would be integrated into the practice setting, acquiring the practice skills and confidence necessary for them to accept responsibility and accountability for the drug therapy outcomes of their patients.

- Pharmacy preceptors would no longer face a constant influx of students who are unfamiliar with the site and require extensive orientation before they are able to assume greater independence, responsibility, and accountability for patient care services.

- Institutions would benefit from the services provided by pharmacy students and, in many cases, would likely be able to expand their patient care pharmacy services.

- $\quad$ Faculties of pharmacy would find it considerably easier to place students in experiential rotations when hosting sites perceive that they are receiving demonstrable value in return for the increased workload associated with hosting students.

\section{BARRIERS TO IMPLEMENTATION}

The tendency of universities and hospitals to work in "silos" on the design, implementation, and delivery of experiential training models needs to be recognized and addressed. The ultimate goal of both parties should be the development of competent, highly qualified pharmacy practitioners, and the process of achieving that outcome must in turn provide value to both.

The regulatory authorities should be involved in the early stages of planning to ensure that the appropriate regulatory framework exists, or is put into place, to support the development of experiential training models in which students play a progressively greater role in the delivery of patient care. For example, in many, if not all, states in the United States, pharmacy students are registered with the state regulatory authority, possess an intern license, and can do anything a licensed pharmacist can do, as long as he or she is working under the supervision of a licensed pharmacist. The ultimate responsibility rests with the pharmacist who delegates an act to a student pharmacist, but students can perform such delegated tasks. In Canada, the ability to delegate pharmacists' tasks to pharmacy students would need to be confirmed in each province where new experiential models, using students as providers of care, were implemented.

The practice of providing direct and constant supervision of student pharmacists needs to evolve into a model where students, after an adequate period of training and assessment of their skills, are given progressively greater autonomy, independence, and accountability for the delivery of clearly defined activities appropriate for their level of training. Although the pharmacist supervisor must provide an appropriate level of supervision, this should not be used as a reason to refrain from delegating appropriate tasks and responsibilities to students. On the other hand, although students are expected to practice more independently in this model than in traditional models, they will not be unsupervised, and it is expected that a pharmacist preceptor (an "attending pharmacist") would meet regularly with students to review their activities and plans.

The belief that students should have the opportunity to see how things are done at a number of different practice sites needs to be balanced against the need for them to become familiar enough with a particular workplace environment that they can begin to actively participate in the delivery of care.

\section{CONCLUSIONS}

Achieving the practice vision laid out by the Moving Forward and Blueprint for Pharmacy initiatives is critical to the future of pharmacy practice in Canada. Redesigned experiential training programs for pharmacy students are needed to assist the profession in making the transition from dispensers of drugs to managers of medication therapy. It is time to redesign experiential training programs to better prepare students with the skills that will be required for them to thrive in the future pharmacy practice models that will evolve as the Blueprint for Pharmacy's Vision for Pharmacy becomes a reality.

\section{References}

1. Task Force on a Blueprint for Pharmacy. Blueprint for pharmacy: designing the future together. The vision for pharmacy: optimal drug therapy outcomes for Canadians through patient-centred care. Ottawa (ON): Canadian Pharmacists Association; 2008 Jun [cited 2012 Jun 15]. Available from: http://blueprintforpharmacy.ca/docs/pdfs/2011/05/11/ BlueprintVision.pdf?Status=Master

2. American College of Clinical Pharmacy; Rathbun RC, Hester EK, Arnold LM, Chung AM, Dunn SP, Harinstein LM, et al. Importance of direct patient care in advanced pharmacy practice experiences. Pharmacotherapy 2012:32(4):e88-e97.

3. Francke DE. Prescription for pharmacy practice 1984. Drug Intell Clin Pharm 1976;10(2):111-112.

4. Bussières JF. Chapter B: Clinical pharmacy services. In: Babich $M$ Bornstein C, Bussières JF, Hall K, Harding J, Lefebvre P, et al., editors. Hospital pharmacy in Canada 2009/2010 report. Eli Lilly; 2010 [cited 2012 Mar 25]. p. 3-20. Available from: www.lillyhospitalsurvey.ca/hpc2/ content/2010_report/ chapter_b\%20.pdf

5. Yuksel N, Eberhart G, Bungard TJ. Prescribing by pharmacists in Alberta. Am J Health System Pharm 2008;65(22):2126-2132.

6. Rosenthal MM, Breault RR, Austin Z, Tsuyuki RT. Pharmacists' self perception of their professional role: insights into community pharmacy culture. J Am Pharm Assoc 2011;51(3):363-367.

7. Al Hamarneh YN, Rosenthal M, McElnay JC, Tsuyuki RT. Pharmacists' perceptions of their professional role: insights into hospital pharmacy culture. Can J Hosp Pharm 2011;64(1):31-35.

8. Management Committee, Moving Forward: Pharmacy Human Resources for the Future. Pharmacy resources: challenges and priorities. Research report. Ottawa (ON): Canadian Pharmacists Association; 2008 [cited 2012 Jun 15]. Available from: http://blueprintforpharmacy.ca/ docs/defaultdocument-library/2011/04/19/Moving\%20Forward\%20PHR\%20Challenges $\% 20$ and $\% 20$ Priorities.pdf?Status=Master 
9. Management Committee, Moving Forward: Pharmacy Human Resources for the Future. Moving forward: pharmacy human resources for the future. Final report. Ottawa (ON) Canadian Pharmacists Association; 2008 [cited 2012 Jun 15]. Available from: http://blueprintforpharmacy.ca/docs/ default-document-library/2011/04/19/Moving\%20Forward\%20Final\% 20Report.pdf?Status=Master

10. Task Force on a Blueprint for Pharmacy. Blueprint for pharmacy: implementation plan. Ottawa $(\mathrm{ON})$ : Canadian Pharmacists Association; 2009 [cited 2012 Jun 15]. Available from: http://blueprintforpharmacy.ca/ docs/pdfs/2011/05/11/BlueprintImplementationPlan.pdf?Status=Master

11. Bluml B. Definition of medication therapy management: development of professionwide consensus. J Am Pharm Assoc 2005;45(5):566-572.

12. Position statement and joint resolution on the Doctor of Pharmacy (PharmD) for the first professional degree at universities in Canada. Association of Faculties of Pharmacy of Canada and Association of Deans of Pharmacy of Canada; 2010 Feb [cited 2012 Mar 25]. Available from: www.afpc.info/downloads/1/AFPC_ADPC_PharmD_Position_ Statement_Resolution_Sept_2010.pdf

13. Bond CA, Raehl CL. Clinical pharmacy services, pharmacy staffing, and hospital mortality rates. Pharmacotherapy 2007;27(4):481-493.

14. Kaboli PJ, Hoth AB, McClimon BJ, Schnipper JL. Clinical pharmacists and inpatient medical care: a systematic review. Arch Intern Med 2006;166(9):955-964

15. Makowsky MJ, Koshman SL, Midodzi WK, Tsuyuki RT. Capturing outcomes of clinical activities performed by a rounding pharmacist practicing in a team environment. The COLLABORATE study. Med Care 2009;47(6):642-650.

16. Mersfelder TL, Bickel RJ. Inpatient medication history verification by pharmacy students. Am J Health Syst Pharm 2008;65(23):2273-2275.

17. Hui Y, Stefaniuk K, Ng J, Seki J, Mahalingam G, Streminsky J, et al. Can a pharmacy student-pharmacist model be used to overcome challenges and sustain admission reconciliation? [abstract]. Can J Hosp Pharm 2011;64(1):70.

18. Ingram S, Orser $S$, Retnasothie R, Fernandes O. How long does medication reconciliation take? [abstract]. Can J Hosp Pharm 2010;63(1):78

19. Lam P, Harrison M, Ingram S, Volling J, Wong M, Huh J, et al. Can pharmacy students effectively partner with pharmacists to support medication reconciliation for patients? [abstract]. Can J Hosp Pharm 2009;62(1):70

20. National Coordinating Office. New Blueprint for Pharmacy projects [news release]. Ottawa (ON): Canadian Pharmacists Association; 2011 Dec 2 [cited 2012 Mar 25]. Available from: http://blueprintforpharmacy.ca/ news/news-story/2011/12/02/new-blueprint-for-pharmacy-projects

21. Accreditation standards and guidelines for the baccalaureate degree program in pharmacy. Toronto (ON): Canadian Council for Accreditation of Pharmacy Programs; 1997 [revised 2006, cited 2012 Mar 25]. Available from: www.ccapp-accredit.ca/site/pdfs/university/CCAPP_accred_standards_ degree_2006.pdf

22. Hall K. Chapter J: Current topics. In: Babich M, Bornstein C, Bussières JF, Hall K, Harding J, Lefebvre P, et al., editors. Hospital pharmacy in Canada 2009/2010 report. Eli Lilly; 2010 [cited 2012 Jun 18]. p. 94-109. Available from: www.lillyhospitalsurvey.ca/hpc2/content/2010_report/ chapter_j\%20.pdf

23. Lindblad AJ, Howorko JM, Cashin RP, Ehlers CJ, Cox CE. Development and evaluation of a student pharmacist clinical teaching unit utilizing peer-assisted learning. Can J Hosp Pharm 2011;64(6):446-450.
24. Johnson TJ, Teeters JL. Pharmacy residency and the medical training model: Is pharmacy at a tipping point? Am J Health Syst Pharm 2011;68(16):1542-1549.

25. Ashby DM. Permission granted. Am J Health Syst Pharm 2011;68(16): 1497-1504.

26. The consensus of the Pharmacy Practice Model Summit. Am J Health Syst Pharm 2011;68(15):1148-1152. Available from: www.ajhp.org/ content/68/12/1148.full.pdf

27. Marrs JC, Rackham DM. Residents' challenging role: preceptee, preceptor, or both? Am J Health Syst Pharm 2010;67(3):239-243.

28. Accreditation standards and guidelines for the professional program in pharmacy leading to the Doctor of Pharmacy degree. Version 2.0. Chicago (IL): Accreditation Council for Pharmacy Education; 2011 [cited 2012 Mar 25]. Available from: https://www.acpe-accredit.org/pdf/FinalS 2007Guidelines2.0.pdf

29. Education: statement on collaborative development, delivery and evaluation of pharmacy curricula (2011). Ottawa (ON): Canadian Society of Hospital Pharmacists; 2011 [cited 2012 Jun 18]. Available from: www.cshp.ca/dms/dmsView/1_S_Curricula_2011.pdf

Kevin W Hall, BScPharm, PharmD, is with the Faculty of Pharmacy and Pharmaceutical Sciences, University of Alberta, Edmonton, Alberta. He is also an Associate Editor for the CJHP.

Emily Lap Sum Musing, BScPhm, MHSC, is with the Pharmacy, University Health Network, Toronto, Ontario.

Douglas A Miller, PharmD, is with the College of Pharmacy and Health Sciences, Wayne State University, Detroit, Michigan.

James E Tisdale, BScPharm, PharmD, is with the Department of Pharmacy Practice, Purdue University College of Pharmacy, Indianapolis, Indiana. He is also an Associate Editor for the CJHP.

\section{Address correspondence to:}

Dr Kevin W Hall

Faculty of Pharmacy and Pharmaceutical Sciences

ECHA 3-228

University of Alberta

Edmonton $A B$ T6G $1 C 9$

e-mail: khall@pharmacy.ualberta.ca

\section{Acknowledgements}

The experiential training discussions that took place among the pharmacy directors of the Toronto Central Local Health Integration Network provided the authors with a starting point for the recommendations contained in this paper. The review of drafts of this paper by Ann Thompson and Cheryl Cox (University of Alberta) is gratefully acknowledged. 